CASE NOTES

\title{
UNUSUAL APPEARANCE IN A CASE OF EALES'S DISEASE*
}

BY

\author{
A. G. CROSS AND D. P. CHOYCE \\ London
}

SUBLUXATION of the lens of the eye may occur as a congenital abnormality and may be due to trauma; it is not often due to other causes.

\section{Case Report}

Male aged 27 years, crane driver, admitted to the Moorfields Unit for ocular tuberculosis at the Whiteoak Hospital, Swanley, on December 1, 1951, with a history indicating vitreous haemorrhages in both eyes during 4 months.

On admission there were extensive vitreous opacities-more marked in the left eye A good red reflex was present in the right eye and a dull red reflex in the left. A retinal detachment seemed to be present at 5 o'clock in the left eye. The family history showed no evidence of tuberculosis and no signs of tuberculosis were found in the patient. No other cause for the haemorrhages was found. Inflammatory signs in the anterior segments have never been present and the eyes have never been painful.

Progress was disappointing. Periods of slight clearing of the vitreous in both eyes

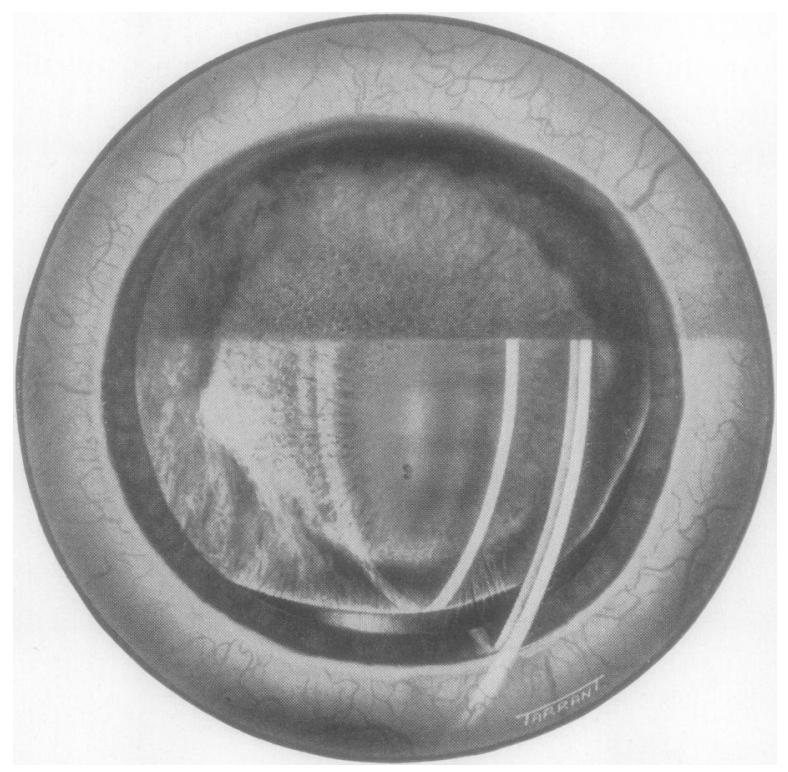

Figure.

* Received for publication January 19, 1953. 
were followed by fresh haemorrhages. Organization of the left vitreous could be seen but the light projection remained fairly accurate in both eyes. It was noticed on July 30 , 1952, that the left anterior chamber had become much deeper than the right and that the pupil was very fully dilated, its normal blue colour being replaced by the brown of the pigmented posterior epithelium of the iris. The lens remained clear but had been displaced backwards and upwards, so that the fibres of the zonule could be clearly made out below. The greenish mass of organized fibrous tissue in the vitreous came forward to the back of the lens. New vessels could be seen on the anterior aspect of this mass, and the circulation of corpuscles within them could be made out with the slit lamp.

The tension of the eye was normal. The vision was reduced to bare perception of light with no projection. These changes had all occurred within 3 days, and 4 months later the appearance of the eye was nearly the same, though possibly the lens had been drawn further up and the iris had been retracted further superiorly so that it could not be discerned without the gonioscope. The appearance of the left eye at this time is shown by the accompanying Figure. After a further 2 months had passed, extensive ciliary staphylomata developed superiorly from 3 to 9 o'clock. The condition of the right eye remained unchanged throughout.

\section{Discussion}

Massive organization had occurred in the vitreous of the left eye of this patient and the new fibrous scar tissue had come forward to the back of the lens and the ciliary body. Its contraction probably caused the backward and upward subluxation of the lens. It is difficult to account for the appearance of the posterior surface of the iris in the pupillary area. The ciliary body has apparently been detached from the scleral spur and drawn backwards. The root of the iris would be drawn back with it, in such a way perhaps, as to present the posterior surface to the front, as seen here. The mechanism by which the ciliary staphylomata were formed is also obscure. The tension of the eye has never been raised to digital examination and there has never been corneal oedema. Inflammatory signs have never been present. Perhaps the degenerative changes of retinitis proliferans spread to and weakened the sclera in this case, so that the normal intra-ocular pressure sufficed to produce extensive staphylomata. Excision is not justifiable because, although almost blind, the eye is neither painful nor dangerous, and histological examination must therefore be delayed. It is possible that such an eye might be excised for suspected neoplasm, as has been emphasized by Neame (1923).

We are indebted to the Medical Illustration Department of the Institute of Ophthalmology for the painting.

\section{REFERENCE}

NeAME, H. (1923). Trans. ophthal. Soc. U.K., 43, 296. 